\title{
Laparoscopic Approach for Management of Hydatid Cyst of Liver
}

\author{
Suman Kumar Shrestha, ${ }^{1}$ Prabin Bikram Thapa, ${ }^{1}$ Dhiresh Kumar Maharjan, ${ }^{1}$ Tseten Yonjan Tamang ${ }^{1}$ \\ ${ }^{1}$ Department of Surgery, Kathmandu Medical College Teaching Hospital, Kathmandu, Nepal
}

\begin{abstract}
Background: Laparoscopy surgery trials are small and unconvincing at present and are limited to higher centers. The objective of the study is to determine the clinical features, prevalence of site of hydatid cyst and complications of this modality of this treatment.

Methods: A cross sectional study was carried out in all patients with one or two hepatic hydatid cyst who underwent laparoscopic management in KMCTH from January 2013 to March 2015 were included in the study. Aspiration, deroofing and evacuation of the hydatid cyst were done.

Results: Twenty six patients underwent laparoscopic management for liver hydatid cysts. Males were seven (65.38\%) and females were $9(34.61 \%)$. The mean age was $35.5 \pm 13.1$ years (range 21-55years.) The commonest complaint was pain and discomfort in $13(50 \%)$ patients and lump in 6(13.06\%) patients. Twenty four $(92.3 \%)$ patients were successfully treated with laparoscopic approach. Two (7.69\%) patients had to be converted to laparotomy because of dense adhesions and bleeding. Mean operation time was $43.6 \pm 10.6$ minutes. Two $(7.69 \%)$ patients had port site infection. One $(3.84 \%)$ patient had bile leak and no recurrence and mortality in our series.

Conclusions: Laparoscopic management of liver hydatid cyst was safe and effective in selective group of patients in equipped hospital.

Keywords: Laparoscopic management; liver hydatid cyst.
\end{abstract}

\section{INTRODUCTION}

Liver hydatid disease is usually asymptomatic but it may cause considerable morbidities and occasional death. ${ }^{1}$ The morbidities include rupture of cyst with intra-peritoneal dissemination, anaphylactic reaction, pressure on adjacent organs, secondary bacterial infection and intra biliary rupture of cyst resulting in obstructive jaundice. ${ }^{2-4}$ The Echinococcus granulosus is the most common causative organism and there are also others organisms, for eg. E. Multilocularis, E. vogeli and very rarely, $E$. oligarthrus. Classically, open surgery is performed but laparoscopic management is associated with low morbidities, quick recovery and short duration of hospital stay .5,6 The minimally invasive procedure may be discouraging because of fear of anaphylactic shock resulting from spillage of hydatid fluid.$^{7,8}$ The treatment should be tailored according to morphology, size, number and location of the cysts. Varieties of managements have been advocated from total pericystectomy, partial hepatectomy, laparoscopic de-roofing, percutaneous aspiration to conservative drug therapy $\cdot^{8-10}$ Laparoscopy surgery trials are small and unconvincing at present and are limited to higher centers. ${ }^{11-13}$

The objective of the study was to determine the clinical features, prevalence of site of hydatid cyst, complications and advantages of this modality of treatment

\section{METHODS}

The study was undertaken after the permission from ethical committee of Kathmandu Medical College Teaching Hospital. This observational study was conducted in the department of surgery from January 2013 to March 2015. Total of twenty six patents with laparoscopic management were included in the study after taking informed consent. All patients were followed for three months for detecting the recurrence of the disease using abdominal ultrasonography. The selection criteria for inclusion into the study were documented hydatid disease by ultrasound and ELISA test, cyst

Correspondence: Dr Suman Kumar Shrestha, Department of Surgery, Kathmandu Medical College Teaching Hospital, Sinamangal, Kathmandu, Nepal. Email: suman_ shrestha@hotmail.com, Phone: 9851032851. 
greater than three centimetre and patient fit for general anesthesia (ASA grade I and II). The patients with previous abdominal surgery, recurrent disease, multiorgan involvement and allergic to albendazole were excluded from the study. ${ }^{14}$ Other exclusion criteria was patients with coagulopathy (PT/INR, BT, CT and platelets), posteriorly located cysts (segment I, VII and VIII), heterogeneous complex cysts(Gharbitype IV)and calcified walled cyst (Gharbitype V). ${ }^{15}$

Clinico-pathological features (abdominal pain and abdominal lump), operation time, conversion to open procedure, morbidity (eg. bleeding, port site infection, port site hernia), recurrence and mortality were recorded. The procedure was done under general anaesthesia. Prophylactic antibiotics (Ceftriaxone $1 \mathrm{gm}$ ) and hydrocortisone (100 $\mathrm{mg}$ ) were administered before the incision. Nasogastric tube and Foley catheter were placed before the procedure. Umbilical port was made, insufflation of peritoneal cavity with carbon dioxide and kept under pressure of $14 \mathrm{~mm}$ of mercury. Zero degree scope was introduced and inspection of the whole abdominal cavity was performed. Another $10 \mathrm{~mm}$ port was introduced through the epigastric port for inserting needle and aspiration of hydatid cyst at most prominent point. Precaution was taken not to spill the fluid contents of the cavity. When aspiration was complete, scolicidal agent, $20 \%$ hypertonic saline was instilled into the cavity and re-aspirated, the third $5 \mathrm{~mm}$ port was kept at right hypo-chondrium to handle the cyst and de-roofing the cyst was done from right hand port. Ten millimeter suction tube was introduced into the cavity and aspirated all laminated membranes and daughter cysts from the cavity.

The cavity was once again irrigated with hyper-tonic saline and evacuated to check any remaining daughter cysts, membranes and biliary leak; drainage tube of wide bore was kept in the cavity through right hypochondrium and fixed by the non-absorbable silk suture for postoperative drainage and omental packing was done in the cavity. The drain was removed after the content and bile drainage has been cleared. If the bile drains for more than three weeks, patient was sent for ERCP papillotomy and stenting. The patients were followed in outpatient department by the consultant for 2, 4 and 6 weeks for assessing the cavity for reoccurrence by ultrasonography. The incidence and percentage for clinical features and complications were analyzed by simple manual calculation.

\section{RESULTS}

Twenty six patients underwent laparoscopic management for liver hydatid disease in the department. There were 17 males(65.38\%) and nine females(34.61\%). The mean age was $35.5 \pm 13.1$ years (range 21-55years). Thirteen patients $(50 \%)$ presented with pain and discomfort in the right hypochondrium. The modes of presentation of the patient are listed in table 1 . The patients presented with pain and mass were six(23.06\%). Two (7.69\%) patients presented with nausea and dyspepsia, one (3.84\%) patient with fever and one (3.84\%) patient with jaundice. Accidental diagnosis of hydatid disease was three(11.53\%) patients on ultrasound performed for other reasons.

\begin{tabular}{|lll|}
\hline $\begin{array}{l}\text { Table 1.Clinical presentation of patient with } \\
\text { hydatid cyst of liver. }\end{array}$ & $\begin{array}{l}\text { Number of } \\
\text { patients }\end{array}$ & $\begin{array}{l}\text { Percentage } \\
\text { (\%) }\end{array}$ \\
\hline Clinical features & 13 & 50 \\
\hline Abdominal pain & 2 & 7.69 \\
\hline Nausea and dyspepsia & 2 & 23.06 \\
\hline Abdominal lump & 6 & 11.53 \\
\hline Accidental discovery & 3 & 3.84 \\
\hline Fever & 1 & 3.84 \\
\hline Jaundice & 1 & 100 \\
\hline Total & 26 & \\
\hline
\end{tabular}

Eighteen (69.23\%) had a single cyst while six (23.06\%) patients had two cysts and remaining two (7.69\%) patients had three cysts. Right lobe, of the liver was more commonly involved (84.61\%) than the left lobe (11.53\%)whereas cysts were bilateral in one case(3.84\%). Table 2

\begin{tabular}{|lll|}
\hline Table2. Location of hydatid cyst in liver. \\
\hline Number of Cyst & $\begin{array}{l}\text { Number of } \\
\text { Patients }\end{array}$ & $\begin{array}{l}\text { Percentage } \\
\text { (\%) }\end{array}$ \\
\hline Single cyst & 18 & 69.23 \\
\hline Two cyst & 6 & 23.06 \\
\hline Three cyst & 2 & 7.69 \\
\hline Location & 22 & 84.61 \\
\hline Right lobe of lever & 22 & 11.53 \\
\hline Left lobe & 3 & 3.84 \\
\hline Both lobe & 1 & 100 \\
\hline Total & 26 & \\
\hline
\end{tabular}

The mean cyst diameter was $11 \mathrm{~cm}$ (ranging from 3 to $19 \mathrm{~cm}$ ). Abdominal ultrasound, CT scan, indirect hemaglutination test and liver function tests were done in all cases. The mean time duration of the laparoscopic management of the liver hydatid cyst was $40 \pm 11.8$ minutes (Range: 30 to 50 minutes). The duration was shorter in small and single cyst. 
List of complications are tabulated in Table 3.: two (7.69\%) patients had port site while two $(7.69 \%)$ patients had to be converted to laparotomy; one patient for uncontrolled bleeding and other for dense adhesion. One patient had continued bile leakage in drain.

Table 3. Complications of the laparoscopic excision of hydatid cyst of liver.

\begin{tabular}{|lll|} 
Complications & $\begin{array}{l}\text { Number of } \\
\text { patients }\end{array}$ & $\begin{array}{l}\text { Percentage } \\
\text { (\%) }\end{array}$ \\
\hline Anaphylactoc shock & 0 & 0 \\
\hline Bleeding & 1 & 3.84 \\
\hline Port site infection & 2 & 7.69 \\
\hline Peritonities & 1 & 3.84 \\
\hline Bile in drain & 1 & 3.84 \\
\hline $\begin{array}{l}\text { Conversion to open to } \\
\text { surgery }\end{array}$ & 2 & 7.69 \\
\hline Recurrence & 0 & 0 \\
\hline Port site hernia & 1 & 3.84 \\
Mortality & 0 & 0 \\
\hline Total & 26 & 100 \\
\hline
\end{tabular}

\section{DISCUSSION}

In this study, we evaluated the laparoscopic management of hydatid cyst in a selected group of patients. The average age of patient was $35.5 \pm 3.1$ which is keeping with the average of presentation in the endemic areas. ${ }^{4,5}$ Males are predominantly affected by the disease in this study. Many studies have reported male predominance ${ }^{4-6}$ while some studies have reported female predominance or equal infestation in either gender. ${ }^{7,9}$ Majority of the patients ( 13 i.e., $50 \%$ ) with hydatid cyst of liver presented with abdominal pain and discomfort which was also been reported by other authors. ${ }^{8,11}$ Abdominal lump was most common pathology found in six (23.06\%) in the right lobe of liver. Similar findings were also reported in other studies. ${ }^{3,9,10,13}$ Three $(11.53 \%)$ patients had incidental finding of hydatid cyst during investigations for other ailments in our study which usually, in non-endemic areas. ${ }^{12,14}$

But now, various other instruments have been devised to evacuate the contents of the cyst without spillage. Becket et al. used a transparent bevelled cannula, Al-Shariff et al used a liposuction cannula and PHS (Palanivelu Hydatid System) not only prevent spillage but also visualize biliary cyst communications. ${ }^{7,9,10}$ We used $10 \mathrm{~mm}$ suction tube connected to suction machine with intermittent suction and stop technique in this study and we didn't encounter any anaphylactic reaction in the patient during the surgery
Various laparoscopic technique described are total peri-cystectomy, aspiration of contents, de-roofing of cyst and omentoplasty. ${ }^{9}, 10$ In this study, 26 patients of hydatid cysts were treated laparoscopically, applying the principles of conventional surgery, including inactivation of scolices with $20 \%$ hypertonic saline, aspiration of cyst contents, de-roofing of the cavity and evacuation of all contents and lastly omentoplasty. Two (7.39\%) patients had to be converted to open laparotomy because of dense adhesion and bleeding. Others have reported conversion rate of four to $25 \%$ because of the same reasons. ${ }^{3,5,6}$ There was no mortality and recurrence in this study. Similarly in other's study, there were $0 \%$ mortality in laparoscopic procedures whereas $4.7 \%$ mortality in open management of hydatid cyst ${ }^{6}$ and recurrence rate was three to 10 percent in open procedures.6,10,11 Conventional open surgeries are associated with increased morbidities like wound infection and biliary fistula. 5,6

Other complications of port site infections and peritonitis were managed conservatively with daily dressing like in other series ${ }^{6,12}$ which healed within one week. One $(3.84 \%)$ patient had port site hernia which was repaired by non-absorbable interrupted stitches. Rooh et al. found $4.6 \%$ of port site hernia formation after laparoscopic surgery. ${ }^{3,12}$ One patient (3.84\%) had continuous bile leakage for three weeks and treated with ERCP. Sphincterotomy and stenting were done and the leakage stopped in five days. Two cases had biliary fistula which needed ERCP and sphincterotomy with closure of bilio-cystic fistula in five days., ${ }^{73}$ The mean operation time in our study was $40.51+8$ minutes whereas it varied from 46 minutes to 90 minutes in other series with open procedures. ${ }^{3,6,16}$ This may be because of better access with laparoscopic procedure. All the patients were followed up to six weeks only because majority of patients belongs to remote areas of Sindhupalchowk and Rasuwa.

\section{CONCLUSIONS}

Laparoscopic management of liver hydatid cyst was safe and effective in selective group of patients in equipped hospital.

\section{REFERENCES}

1. Ersan A, Mustafa S, Kemal Ö, Celalettin V, Faruq A, Yahya $\mathrm{P}$, et al. The management of liver hydatid cysts by percutaneous drainage. Can J Surg. 2001;44:2039. [Link]

2. Raheem AB. Laparoscopic treatment of hepatic hyda- 
Laparoscopic Approach for Management of Hydatid Cyst of Liver

tid disease. WJOLS. 2009;2:35-9. [Link]

3. Rooh UM, Khawar K, Jawad K, Tamjeed G, Saira F. Laparoscopic treatment of hepatic hydatid cyst. J Coll Physicians Surg Pak. 2011;21:468-71. [Full Text]

4. Palanivelu C, Jani K, Malladi V, Senthilkumar R, Rajan PS, Sendhilkumar K, et al. Laparoscopic management of hepatic hydatid disease. JSLS. 2006;10:5662. [Link]

5. Viral GS, Dimple AM, Priyanka G, Kishore J. Role of laparoscopy in hydatid cyst disease. J Med Sci. 2014;3:35-7. [Full Text]

6. Bhadreshwara KA, Amin AB, Doshi C. Comparative study of laparoscopic versus open surgery in 42 cases of liver hydatid cyst. IAIM. 2015;2:30-5.

7. Padhy BP, Hota PK. Laparoscopic management of a large hydatid cyst of liver. Bali Med J. 2015;4:140-2.

8. Haitao L, Yingmei S, Tuerganaili A, Jinhui Z, Kafayat K, Qinglong M, et al. Laparoscopic approach for total cystectomy in treating hepatic cystic echinococcosis. Parasite. 2014;21:1-7. [Link]

9. Sahoo MR, Kumar TA, GowdaM. A novel laparoscopic technique for drainage of hydatid cyst in posterior segment of liver. Int J Case Rep Imag. 2013;4:194-8. [Link]

10. Graur F, Hajjar NA, Mois E, Furcea L, Elisei R. Lapa- roscopic treatment of hydatid hepatic cyst. Advanced Laparoscopy. 2016;1:2-16. [Full Text]

11. Anand S, Rajagopalan S, Mohan R. Management of liver hydatid cysts- current perspectives. Med J Armed Forces India.2012; 68:304-9. [PubMed]

12. Dalvi AN, DespandeAA, Prabhu R, Rao PP, Agrawal JB, Bapat RD. Laparoscopic management of hydatid cyst of liver. Indian J Gastroenterol. 2000;19:81-2. [PubMed]

13. Shaw JM, Bornman PC, Krige JE. Hydatid disease of the liver. S Afri J Surg. 2006;44:70-2, 74-7. [PubMed]

14. Isabela MD, Maria DP, Constantin CP, Anca MR, Roxana B, Liviu D. Laparoscopic approach of hepatic hydatid double cyst in paediatric patients: difficulties, indications and limitations. ROJSP. 2016;1:60-7. [Link]

15. Polat P, Kantarci M, Alper F, Suma S, Koruyucu MB, Okur A. Hydatid disease from head to toe. Radiographics. 2003;23(2): 475-94.

16. Smego RA Jr, Bhatti S, Khaliq AA, Beg MA. Percutaneous aspiration-injection-reaspiration drainage plus albendazole or mebendazole for hepatic cystic echinococcosis: a meta-analysis. Clin Infect Dis. 2003 Oct;37(8):1073-83. [Link] 